Article

\title{
Framing the Sun and Buildings as Commons
}

\section{Jeffrey R. S. Brownson}

Department of Energy and Mineral Engineering, The Pennsylvania State University, 265 Materials Research Laboratory, University Park, PA 16802, USA; E-Mail: solarpower@psu.edu; Tel.: +1-814-867-4227; Fax: +1-814-865-3248

Received: 7 August 2013; in revised form: 3 September 2013 / Accepted: 13 September 2013 / Published: 25 September 2013

\begin{abstract}
This study frames integration of Solar Energy Conversion Systems (SECS) with the built environment, addressing on-site limitations for resource allocation in the urban context. The Sun, buildings, and solar technologies are investigated as resource systems within Ostrom's framework of the commons and shared governance, with associated goods (as resource units) appropriated from light conversion (products of daylight, heat, power, shade, money). Light is transient and unevenly distributed across the hours of the day across the year. Building surfaces utilized to convert light into useful products such as electricity are often "area-constrained" and cannot provide total power to all occupants in urban structures. Being unevenly distributed over time and being area-constrained makes the appropriated goods from the solar resource system scarce to commercial buildings and multi-family residences. Scarce commodities require management strategies to distribute the variable returns derived from technologies such as PV and solar hot water. The balance between sustainable urban communities and limited surface area to deliver solar products to all occupants will soon drive communities to consider how the solar goods are managed and allocated. Examples demonstrate management of solar resource and associated goods through collective actions of local communities via utility sponsored models, solar gardens, and crowd-sourced investment.
\end{abstract}

Keywords: solar; common pool resource; solar utility

\section{Introduction}

We seek to improve our awareness of the Sun and the variable solar resource in relation to the local built environment, society, and the surrounding ecosystem services (see Figure 1). The shortwave light 
from the Sun (the spectrum from approximately 280 to $2500 \mathrm{~nm}$ ) can be converted and appropriated by society as a broad array of useful products: daylight, biochemicals affecting physiological and psychological health, thermal heat, electrical power, food, as well as financial returns. When we wish to avoid solar gains, we can use alternate shading strategies to avoid the monetary costs of applying HVAC cooling. Each of these conversion technologies (buildings, solar thermal panels, photovoltaics, and shading systems) will be called Solar Energy Conversion Systems (SECS).

Figure 1. Schematic of the solar ecology tied to the central technologies of a SECS. Three center rings reflect interactions among solar technology (core), client, and locale particular to the goal of solar design: to maximize the solar utility for the client in a given locale.

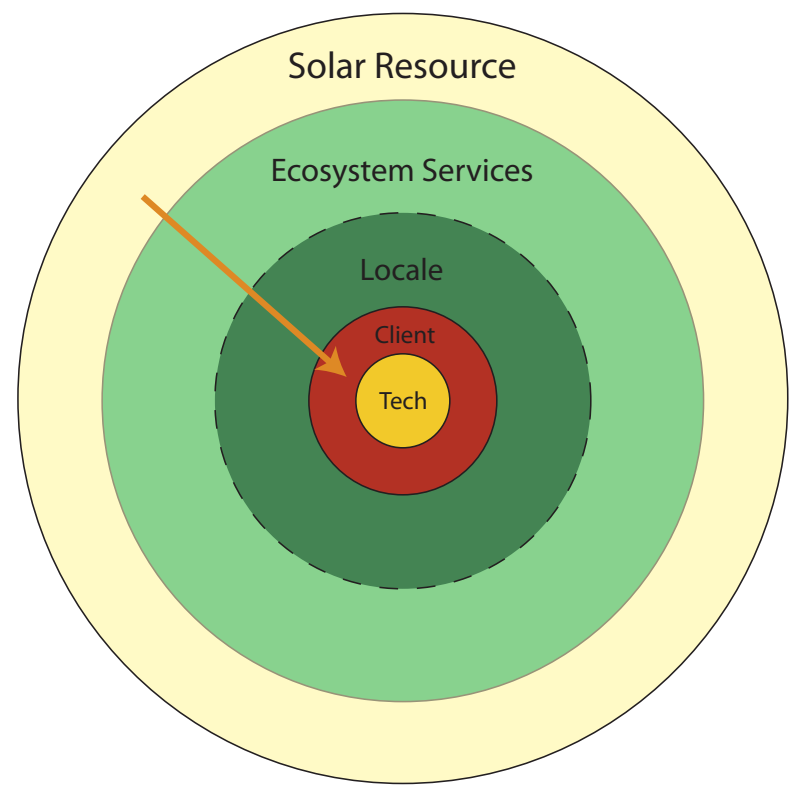

The expansion of the solar industry is driving this goal to improve our understanding, which has seen an explosion of growth globally. The solar electric industry (in terms of photovoltaics, PV) in the USA alone has doubled in scale seven times within the past decade, and solar energy technologies benefit greatly from widespread social acceptance. The Swanson Effect, posed by Richard Swanson of SunPower (similar to Moore's Law in microelectronics), poses that costs for photovoltaic cells fall 20\% for each doubling of global PV capacity. In 1977, PV modules cost $\$ 76.67 / W_{p}$ (in present dollars), but as of 2013 the cost has dropped to $\$ 0.74 / W_{p}$. This means more than 20 doublings have occurred globally in 36 years [1]. The accessibility of PV has intensified design interest to integrate PV with the building system, particularly building exterior surfaces (e.g., façades/roofs). The increased interest in PV has also spurred interest in other solar technologies linked to buildings.

And yet, building systems are effective SECS of their own kind (see Figure 2), converting light into useful product [2]. As seen in Table 1, when coupled to building systems, the appropriated products/goods from the Sun come in the form of daylight, thermal increase, produce from roof gardens, and avoided sun from shading strategies and green roofs. Solar products appropriated for commercial scale built structures and multi-occupant residential structures will be shown to be "area-constrained" with respect to solar access, and hence will be scarce in economic terms. In area-constrained cases, there is a competition for solar services (e.g., daylight vs. solar power). In the explored cases for the 
urban context, solar products of electricity and hot water from PV and solar hot water will be posed as trade-offs for other goods and services derived from the building directly. The volume of the urban structures are large, the occupants numerous, while the surface area receiving the Sun's light is restricted and often selective or time-sensitive. Thus, the derived solar goods are scarce, an impetus for change and new solutions in the process to manage SECS integration with the technological ecosystems of the locale.

Figure 2. Schematic diagramming shortwave sunlight interacting with the Building and surroundings as a Solar Energy Conversion System.

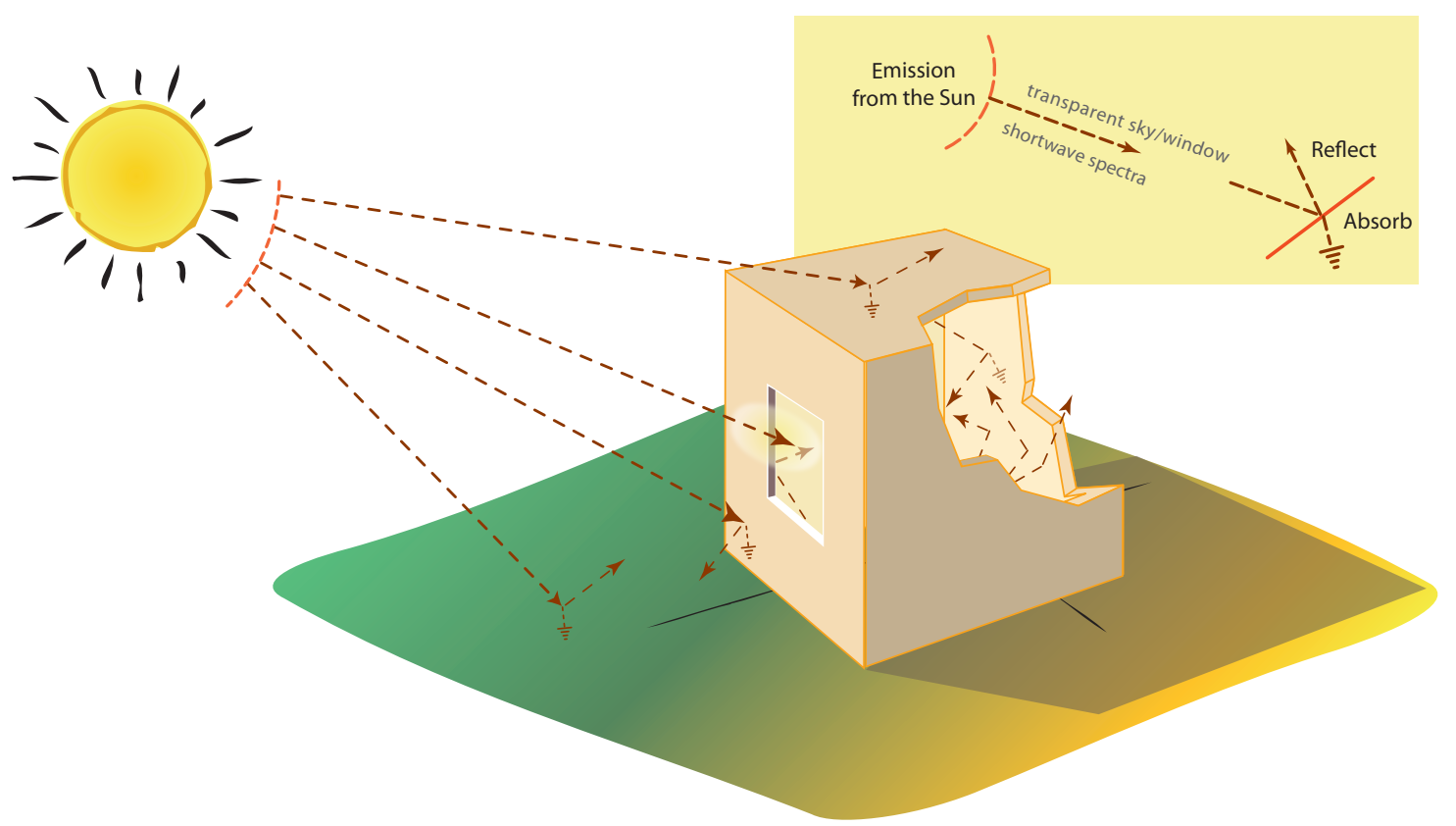

Table 1. Technologies for solar energy conversion systems related to buildings.

\begin{tabular}{cc}
\hline $\begin{array}{c}\text { SECS } \\
\text { (Resource Systems) }\end{array}$ & $\begin{array}{c}\text { Converted Products } \\
\text { (Resource Units) }\end{array}$ \\
\hline Parasols/Awnings & shade \\
Photovoltaics & solar electricity \\
Roof gardens & produce (food) \\
Solar thermal & hot water/air \\
Windows & interior daylight and passive heat \\
\hline
\end{tabular}

In an NREL technical report assessing potential for rooftop PV, Denholm and Margolis estimated that a relatively low fraction of roof space will be suitable for photovoltaics in the USA. They broadly estimated usable residential rooftop access from the building fleet as $22 \%$ in cool climates, and $27 \%$ in warm dry climates. In comparison, $65 \%$ and $60 \%$ were estimated for commercial buildings, cool and dry climates respectively [3]. Hence, even though rooftops can provide a majority of power production in comparison with other façade orientations, the usable resource system is further limited by physical constraints of shading, roof equipment, and building density. And yet, in SECS project development, creative new community shared solar strategies are emerging each year [4]. 
It is a thesis of this paper that the balance between (1) limited surface area for building systems to deliver solar goods to the occupants and (2) the drive to design for sustainable urban communities will soon drive communities to consider how the solar goods are managed and allocated. Scarce goods and services require management strategies, often through market or government actions. However, appropriators of solar energy products, in terms of units of heat/power/illumination/shade/money, find themselves interdependent among each other and tied to network pools such as the power grid and public lands, in addition to the physical resource of the Sun. When light from the Sun and associated goods and services for SECS are framed as common pool resources, then the process to manage SECS integration into the technological ecosystem of the locale can emerge as a collective action challenge.

Design and integration of Solar Energy Conversion Systems (SECS) with the built environment requires a whole systems approach and a transdisciplinary team of contributors. Solar energy has a bright future, and as designers, planners, and engineers, we must prepare for solar to emerge along new frontiers. With expansion of interest and adoption, the next generation of solar research will continue to expand upon systems-based knowledge, incorporating a great diversity of approaches. In turn, the broad field solar energy discovery within the context of the environment, society, and technology could be termed solar ecology: interactive systems study of solar energy within the context of the environment, society, and technology. Here, the solar ecology of the PV-building is explored to present cases where the derived electricity in urban buildings can be found to be scarce, requiring strategies for additional near-site renewable generation.

The framework for addressing the Sun, SECS, and buildings in shared resource management are addressed in a sequence of sections. As the language needed to address the context of problems in resource management and design is new to the buildings audience, the role of resource systems and resource units along with appropriation and provisioning problems for common pool resources is described. The typology of goods (private, club, public, common) is revealed and put into the context of building systems, the Sun, and SECS products. The criteria for making design decisions in provisioning problems is framed in terms of solar utility for the client in the affected locale, followed by energy simulations of building surfaces as area-constrained for PV systems, given annual electricity demands of urban buildings. Finally, current cases are described in practice, where SECS are treated as common pool resources that are coupled to, yet extend beyond the surface of the building to meet increased solar utility for clients.

\section{Resource Systems/Units and Provisioning/Appropriation}

Language use is critical in analyzing goods and services. Nobel laureate Elinor Ostrom specified an imperative "to distinguish between the resource system and the flow of resource units produced by the system" [5]. Here, the resource system is effectively referring to the greater stock from which the good is appropriated. In compliment, the resource units refer to the flow of goods being produced. As seen in Table 2, researchers have framed example resource systems and associated resource units from some common cultural frameworks [5]. In Figure 3, we illustrate the Sun and SECS as resource systems, with the associated resource units. 
Table 2. Example resource systems and resource units.

\begin{tabular}{cc}
\hline Resource System & Resource Units \\
\hline areas for grazing & tons of fodder consumed \\
fisheries & tons of fish harvested \\
bridges & cars/bicycles crossing bridge \\
parking garages & cars parked per day \\
aquifers & cubic meters of groundwater withdrawn \\
\hline
\end{tabular}

Figure 3. Schematic of the Sun (and emitted shortwave light) as a resource system, and the resulting resource units that are appropriated by the clients who own a solar energy conversion system.

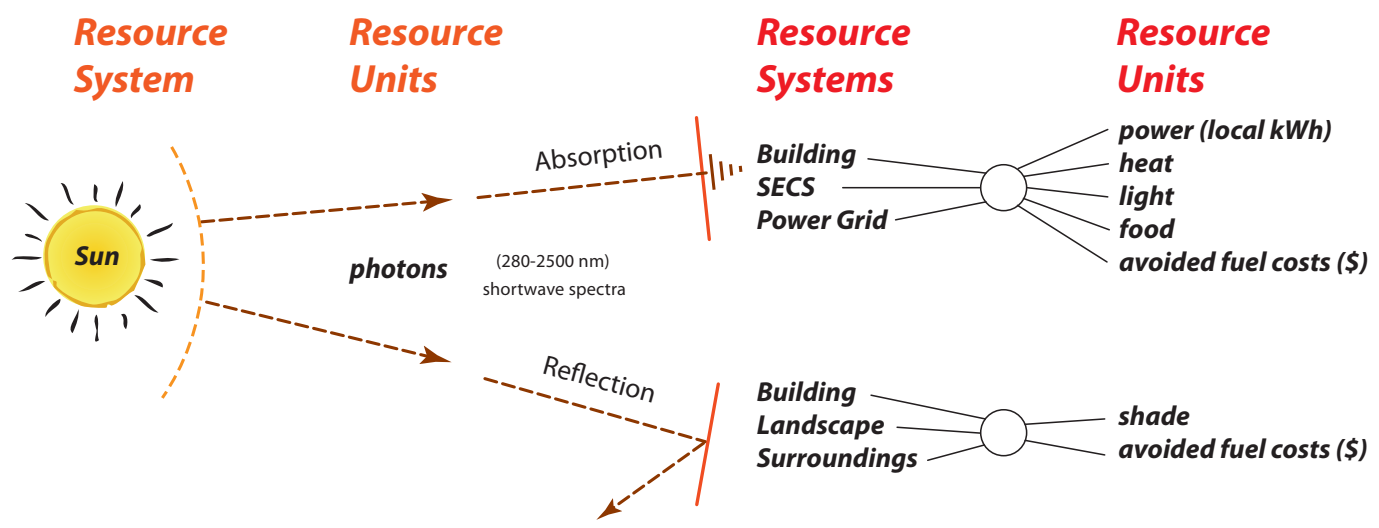

Using the terminology of Ostrom, teams or individuals that arrange for the provision of a resource system at multiple levels, to ensure long-term stability or sustainability of that system, are termed providers, and those who construct, commission, and maintain access to the system are termed producers [5,6]. Distinct from providers are individuals who use or appropriate resource units from resource systems, termed appropriators. Problems having to do with the commons can be framed as either challenges to provisioning for resource systems or challenges to appropriation of resource units. Both are linked, so that solutions for one set will influence solutions for the other.

It is by distinguishing the resource systems from the resource units, and by describing the linked relationship among clients as appropriators and design/construction teams as provider/producers, that we reveal common challenges in shared governance of the solar and building resources. The Sun is an energetic resource system that provides the flow of light in the shortwave band (280-2500 nm). There are subtractable (rivalrous) resource units derived from sunlight, as seen in Table 3. When resource units are "subtractable", or rivalrous, then the use of that resource unit by one will prevent another from using that resource unit simultaneously. In a parking garage, two vehicles cannot occupy the same space at the same time, making the spaces rivalrous. The building system and the SECS can also be framed as resource systems, with rivalrous resource units to manage as a collective action problem. The overlap of the three: Sun, building, and SECS, offers an excellent context to frame future studies in localized resource management, called "common pool resource" problems. 
Table 3. Resource systems and resource units in SECS.

\begin{tabular}{cc}
\hline Resource System Resource Units & Designed and Managed Appropriated \\
\hline collective pool & subtractable \\
\hline the Sun & solar electricity \\
interior daylighting & passive heating \\
shade \\
solar hot water \\
produce (food) \\
SRECs \\
avoided fuel costs \\
the building & offices/apartments \\
& windows \\
& electricity \\
\hline
\end{tabular}

An appropriator uses the resource units from the SECS (e.g., daylight, heat, power, shade, money), and in doing so, effectively subtracts available resource units from another potential appropriator. In a trivial sense, the local solar electricity within the building either goes to power my computer or it goes to my neighbor within the same building, we cannot "share" electrons on our two laptops. Additionally, the solar resource units can be used as inputs for production of other derived resource units, such as a financial return from selling electricity to the grid, or selling solar renewable energy certificates (SRECS), or even the avoided cost of purchasing fuel due to a local SECS. Solar resource units like electricity from local PV can also be immediately transferred to other participants, which is done via Power Purchase Agreements (PPA) [4].

The design team are provider/producers that can help to construct, repair, or make improvements on a resource system, to ensure the long-term sustenance of that system. They can help to reduce the need to demand a resource unit (energy efficiency approaches), they can work to design a larger system for the clients, or they can design methods to ration the flow of resource units. Provisioning/providing problems in solar energy are tied to the resource systems that offer the potential access to resource units. The Sun is an intermittent resource system at the Earth's surface, and design challenges are tied to the locale, both in terms of time scale and terms of spatial coordinates (latitude, collector orientation). Variability of the solar resource can be studied by minute/hour/day/season, to better understand the uncertainty of the flow of light in a given locale [7]. As such, SECS design is a time-dependent problem. Buildings and solar technologies are intermittent resource systems with design challenges tied to locale and occupant behavior.

Characteristics of both provisioning and appropriation problems are presented in Table 4. Provisioning problems may occur on either the supply side, related to the design, construction, commissioning, and repairs of the resource system; or they may occur on the demand side, related to regulating or rationing rates of resource unit withdrawal from the system. Provisioning problems 
are time-dependent challenges; planning is central for a stable resource system given the constraints of both variable time scales of resource unit production and of client demand schedules. In contrast, appropriation challenges seek to allocate a fixed quantity of resource units so as to reduce uncertainty, to reduce conflict among stakeholders in assigning rights, and to avoid rent dissipation (where the marginal returns are smaller than the marginal costs of appropriation). Appropriation challenges are considered as time-independent, as appropriators seek returns on their resource units within the given moment [5].

Table 4. Challenges in management of resource problems.

\begin{tabular}{cc}
\hline Provisioning Appropriation & Problems Problems \\
\hline time-dependent & time-independent \\
planning, managing & allocating \\
resource systems focus & resource units focus \\
either supply/demand side & demand side \\
\hline
\end{tabular}

\section{Typology of Goods}

Goods can be typed by two primary conditions for access: excludability and rivalry, where both conditions can be associated with a good from low to high levels. The condition of high excludability means that access to a good can be intentionally restricted in some way, whereas low excludability means that one cannot easily restrict access to the good. High rivalry means that the goods are subtractable, or the appropriation of a good takes away from another's ability appropriate that good. Low rivalry (independent of excludability) indicates that subtraction of a unit of the good does not take away from the ability of another to use the good [5,8].

As seen in Figure 4, the conditions of excludability and rivalry lead to four types of goods: private, club, public, and common goods. Both public and common goods can be appropriated by large portions of society (low excludability). A common good is distinguished from a public good by the nature of how the resource units are appropriated from the resource system. Public goods (air, knowledge, national defense) have non-subtractable resource units while being non-exclusive.

We can also use the terminology of resource systems and resource units to help in classifying goods for the Sun, SECS, and building systems. The resource system can be a good, accessed as a stock, while the resource units are also goods, appropriated as a dynamic flow. In particular, common goods have subtractable resource units (making it highly rivalrous) and low excludability. For example, the parking spaces within a public garage (see Table 4) are resource units for the parking garage resource system. The spaces cannot hold multiple cars at the same time, and as such are subtractable (highly rivalrous), yet in a community/public parking lot one does not exclude individuals from parking in the available spaces (low excludability). Hence, the parking spaces are common goods. So to the PV array on a public building is a resource system that may be classified as a public good, while the electrons provided by solar conversion (photovoltaic effect) are resource units that may be explicitly subtractable when coupled to the building system and the adjoining power grid (a common good), as electric power generated will be shared and sold among the grid. 
Figure 4. Typology of goods according to degree of excludability and rivalry (subtractability) [5].

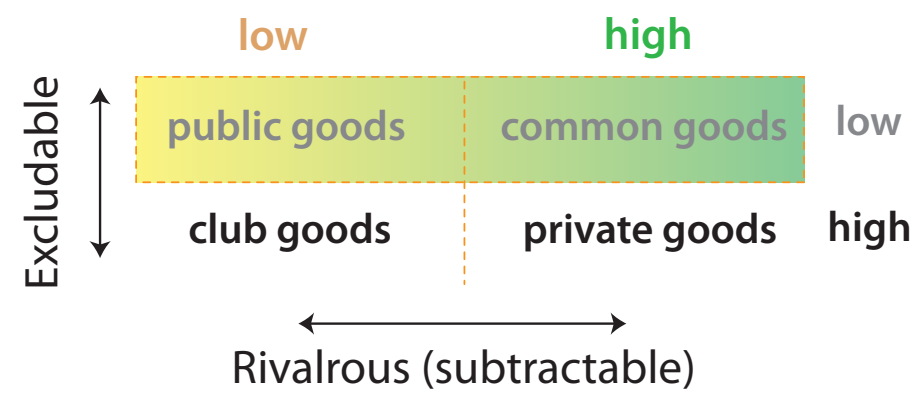

If apartments are the resource units of apartment buildings (resource system), we can assess that (under rental or ownership rights) apartments are subtractable, much like parking spaces, and excludable, like private parking spaces. Hence, under rental or ownership conditions, apartments are private goods. In contrast, a shared recreation facility like a pool within the apartment complex (such that only apartment occupants and guests are permitted entry) has non-subtractable resource units, and would be a club good.

The Sun is a shared resource system for all, a public good for society on a global scale, while the photons emitted are subtractable resource units. Access to the resource units from the solar energy budget is constrained by the conditions of the locale in terms of latitude, meteorology, topography, and local shade/reflectance coming from surrounding built structures or trees. Light is also transient, or constrained in time-having a time-dependent and limited flow of energy that is not stored as a stock. These influential temporal factors are also locally derived, or dependent upon the client's locale. Hence irradiance from the Sun can be seen as both globally distributed and locally specific at the same time.

We can identify scenarios in which an individual's appropriation of the Sun's light (or the technologies applied to converting light to useful resource units) is found to be rivalrous. If one has a tall tree (which uses light for photosynthesis) that grows to significantly block a neighbor's PV system, we create a rivalry for the solar good. An electronic device like a photovoltaic module purchased by an individual client could be framed as a private good (excludable and rivalrous), but it might also be purchased and managed by a community to be shared at a library, office space, or multi-family structure. Under such a condition, the electronics could be considered a common pool resource.

The power grid is another resource system that behaves as a gradation between a public and a common pool resource, connecting the pools of building and PV systems together within the solar ecosystem. Much like a bridge or roadway, the power grid is congestible, in that added appropriators will drive the resource units from a low to high rivalry (a crowded bridge or a congested grid) tending from a public to a common good [9].

As seen in Table 5 the electricity grid in the USA has shared ownership models [10]. However, while the resource system of the grid may be an admixture of private and public goods, the resource units (electrons, or power) are subtractable, and thus the appropriated power can be either a common or a private good. For example, the independent power that one family produces on an off-grid PV home is effectively a private microgrid (power as private goods). The power produced by grid-tied PV for a local building (or solar garden) is non-excludable and subtractable, hence a common good. 
Table 5. Ownership Breakdown for the USA Electricity Grid, in percent breakdown for generation and transmission [10].

\begin{tabular}{ccc}
\hline Owner Group & Generation (\%) & Transmission (\%) \\
\hline Investor-owned utilities & 50 & 80 \\
Public-owned utilities & 25 & 20 \\
Independent power producers & 25 & 0 \\
\hline
\end{tabular}

Common goods and services can be very interesting within the context of society and sustainability. The organization, allocation, and management or governance of a commons can be tied to two concepts: the resource system (a system with stocks) and the resource units that flow from the system. Resource systems can have multiple kinds of stocks, called stock variables, from which a maximum quantity of a flow variable may be collected without harming the particular stock or the resource system as a whole [5]. The broader issues of excludability in the solar field have been addressed in the past through the legal precedent of solar access and solar rights $[11,12]$.

\section{Building Systems as Area-Constrained Resource Systems}

One can illustrate the upper bounding scenarios where the size of the SECS from a technology such as photovoltaics does not meet the annual electric demand for the building, nor the multi-occupant demand if split proportionally. Building systems are also resource systems, coupled with the Sun as a SECS, and also coupled with the energy stored in the ground, the contributions of people as occupants, and outside fuel consumption from geofuels (non-renewable stocks of energy resources embedded in Earth's crust; coal, oil, natural gas, and fissile elements). Buildings can also be area-constrained relative to PV integration when large fractions of power are desired to be produced on-site.

Looking at either a medium commercial office space or a multi-occupant midrise apartment complex (examples in Table 6), one observes the following: the volume is large, the occupants are numerous, and the energy density demand is high [13-15]. Additionally, the area for solar resource unit appropriation is selective, anisotropic over the day, and scarce. Scarcity drives the design team to think of sustainable solutions that provide a high solar utility for the clients, as well as energy resource management solutions that are coupled to the building system, yet go beyond the enclosed space.

Buildings are diverse in proportions and orientation, but a simplified comparison of urban structures can be explored as a thought experiment. One can assess the power scarcity (in kWh or MWh) derived from PV systems integrated with a building in an urban environment using available dynamic simulation tools and derive the solar fraction of annual PV power derived from extensive integration into the roof and façades. 
Table 6. Energy simulation parameters for photovoltaic cladding $[13,14]$.

\begin{tabular}{ccc}
\hline hlMetric & Medium Office & Midrise Apartment \\
\hline Stories & 3 & 4 \\
Floor height $(\mathrm{m})$ & 3.96 & 3.05 \\
Building height $(\mathrm{m})$ & 11.88 & 12.2 \\
\hline Long Façade length $(\mathrm{m})$ & 50 & 53 \\
Long Façade area $\left(m^{2}\right)$ & 593 & 648 \\
\hline Short Façade length $(\mathrm{m})$ & 33 & 20 \\
Short Façade area $\left(m^{2}\right)$ & 396 & 240 \\
\hline Total floor area $\left(m^{2}\right)$ & 4982 & 3135 \\
Roof area $\left(m^{2}\right)$ & 1662 & 1045 \\
\hline Occupants & 200 & 358 \\
\hline
\end{tabular}

\subsection{Methods for Simulation}

Using the available data from the US DOE Commercial Reference Building Models from the national building stock, two typical structures were selected [13,14]. In Table 6, building proportions are displayed for a 3-story medium commercial office building and a 4-story mid-rise apartment complex [14]. Energy intensities for the built structures were drawn from the US DOE Energy Information Administration's 2003 Commercial Buildings Energy Consumption Survey (CBECS) [15].

The software SAM (System Advisor Model) was used to simulate PV power production from each of the simple surfaces for the structures [16,17]. A detailed PV-inverter component performance model was applied to the simulation, responsive dynamic hourly irradiation conditions and to thermal influence on the PV module performance $[18,19]$. In this case, the PV panels were selected as highly efficient single crystal silicon modules $(\eta=17.3 \%$ ) and assumed to be mounted flush with each façade to render the entire surface opaque (no window access). Effectively, the buildings each act as a simple photovoltaic box. For the simplified purpose of this estimate each structure was oriented along a long East-West axis to expose a large southern façade. The locations of Phoenix, AZ and Philadelphia, PA were selected to represent two urban settings in different climate regimes.

\subsection{Simulation Results}

The results of the simulation study are summarized in Table 7. Annual PV gains are presented as electrical energy produced on-site from the building surfaces. For the medium commercial office space described by the US DOE, in Phoenix, Arizona: $63 \%$ of the PV electricity comes from the roof, $15 \%$ from the South façade, $9 \%$ from the East, $8 \%$ from the West, and 5\% of the remaining energy is derived from the North.

Annual electric energy demand of a typical medium commercial office building is estimated at 0.954 MWh (West, Mountain census region and division) [15]. Knowing the annual demand, the 
building-SECS system would appropriate a solar fraction of $F=0.47$ from the roof alone (where $F$ is the net share of annual solar energy gains provided by the PV system). The solar fraction is $F=0.24$ from the $\mathrm{S} / \mathrm{E} / \mathrm{W}$ façades combined. The entire building would be required for PV to provide $F=0.74$, $74 \%$ of the net annual electricity demand for the whole building. Hence, with no access to windows for daylighting, the entire clad structure would still be insufficient to deliver annual energy demands. Of course, the actual solar resource is intermittent, and without energy storage, a provisioning challenge emerges for managing both solar resource unit supply, and occupant demand.

Note that a change in the climate regime does not dramatically change the distribution for the same scale medium commercial office space. When set in Philadelphia, Pennsylvania, 61\% of the PV electricity is appropriated from the roof, while $17 \%$ is derived from the South façade (Northeast, Middle Atlantic census region and division) [15]. A solar fraction similar to Phoenix is collectively appropriated, given the solar resource driving the building is only $75 \%$ that of the American Southwest and reduced annual power demands occur in tandem with reduced power production [15].

Table 7. Simulation results for local power derived as annual PV gains, reported as a percent contribution to the net solar electric energy production in the building.

\begin{tabular}{ccccc}
\hline Surface & AZ Office (\%) & PA Office (\%) & AZ Apartment (\%) & PA Apartment (\%) \\
\hline Roof & 63 & 61 & 55 & 53 \\
South & 15 & 17 & 25 & 25 \\
East & 9 & 8 & 7 & 7 \\
West & 8 & 8 & 7 & 7 \\
North & 5 & 6 & 6 & 8 \\
\hline
\end{tabular}

As noted in Table 7, for a simple 4-story midrise apartment complex in Phoenix, AZ, the shared power output is quite similar to that of a medium office building, although less power would be appropriated from the rooftop and more from the southern exposure (25\% of the PV energy comes from the South facade and 55\% from the roof). Given the building footprint, an annual demand for electric energy is estimated at $0.601 \mathrm{MWh}$. Hence, the occupants could collectively appropriate $47 \%$ of their annual electric demand (solar fraction of $F=0.47$ ) from the roof alone (and $F=0.31$ from S/E/W). The entire building would be required for local PV to provide $85 \%(F=0.85)$ of the building's collective annual demand for electricity. The same scale midrise apartment complex in Philadelphia, PA demonstrates a similar profile to that in Arizona: $25 \%$ of the PV power from the South façade, $7 \%$ comes from the East/West each, and 53\% from the roof. Again the solar fraction in Philadelphia is effectively the same as in Phoenix, but scaled in magnitude due to reduced solar conditions [15].

In each of the four sample structure illustrations, one should not assume that it is a rational or even compelling strategy to clad an entire structure in PV for the sole purpose of providing solar-derived electricity. The thought experiment serves only to present an upper bound for the integrated PV-Building (cladding the envelope with PV) as a form of commons or resource system for appropriating resource units of electricity. Resource systems such as SECS have theoretical limits achieving a maximally efficient "flow" of goods or services [5]. As such, the examples demonstrate flow-limited nature of 
renewable systems when there are area-constraining factors for SECS deployment, as in medium to large buildings with many occupants characteristic of urban settings.

\section{Solar Utility}

The clients or stakeholders who demand and allocate solar products from a local SECS are appropriators, either from direct ownership or via leasing partnership with a third party owner. From an economics stance, clients of building systems seek to maximize their utility, based on their needs for the good. Here, solar utility refers to the preference of the clients/stakeholders for a distinct set of goods and services that originate from the solar resource system. In order to describe a general approach to appropriating the goods and/or services (as resource units) from the solar resource system and solar technology resource systems, we pose the integrated perspectives of the collective clients or stakeholders tied to a specific multi-occupant building with the design team responsible to provide access to the solar resource and manage a sustainable and preferential supply of the derived solar resource units (e.g., electricity, daylight, cool space).

The goal of solar energy design and engineering could be posed as such: to maximize the solar utility for a client or group of stakeholders, within their given locale. The transdisciplinary practitioner teams in solar energy systems design and engineering work to arrange for the provision, or long-term sustainable access of a resource system such as power from the Sun. An effective SECS implementation has high solar utility for the client/stakeholders in that given locale. Design teams can develop compelling cases for SECS adoption by the client or stakeholders in being more knowledgeable about the solar resource and its applications. The design and management of a SECS is both a challenge in appropriation and in provisioning [5].

The modeling illustration opens the question for solar utility among the building occupants. A fully clad PV envelope would be totally opaque to light. Which is of higher preference among solar goods: access to daylight, or access to renewable electricity? Divided proportionally among occupants, the solar derived electricity would yield $2-5 \mathrm{kWh}$ per person per year in each case (effectively returning less than a dollar a year). In addition, with the annual variability of the solar resource, the yield with respect to building orientation, geometry, and local shading constraints, this challenge only becomes more difficult and complex. Hence, one can directly observe how the products of the solar resource system, the solar resource units can rapidly become scarce commodities, suggesting higher utility in a shared allocation of resources as a commons.

\section{Cases for Solar Commons}

The work of community solar development is expanding the legal space surrounding solar access, solar rights, regulation, and market inefficiencies. A case emerged from the Solar Commons Project in Phoenix, AZ ([20]). The organizers from the Solar Commons Project established a community land trust dedicated to local social equity, allowing new solar properties to be held ("in trust") on behalf of the community. The goal of the non-profit community-shared solar venture is to establish photovoltaic systems in the public right of way zones (e.g., streets, another commons) and maintain them as a part of the commons for the community. The Solar Commons Project is one example of a provisioning solution 
for the resource system providing renewable electricity. While not distinctly a buildings context, the work is emphasizing transparency, accountability, and access as key principles of a successfully managed commons. The Solar Commons has demonstrated the use of trusts in solar energy solutions as a powerful tool for civic organizations to partner with government and investors, growing a commons sector of the green economy [20].

Large scale utility solar energy projects (typically greater than $1 \mathrm{MW}$ peak DC capacity) are termed solar farms, and as such smaller scale establishments are being termed solar gardens. Solar gardens are common pool resource system for derived solar resource units, wherein subscribers may purchase a share of the allocated PV power to receive a credit on their personal electric bills. The distinct advantage of the solar garden is that one may achieve a "virtual net metering", relevant to urban settings. That is, the occupied structures do not require direct access to sunlight (e.g., shaded by trees), yet the subscribers receive credit for the electricity appropriated from the solar garden. The US Department of Energy has classified this as a utility sponsored model of community shared solar [4]. The Solar Gardens Institute was formed in Colorado to organize and educate communities into developing solar gardens as engines for community development. Depending on regional/state regulations, solar gardens may be scaled from as small as tens of kilowatts to as large as tens of megawatts (blurring the line between "garden" and "farm") [21].

Finally, crowd-sourced photovoltaic projects are also emerging. The photovoltaic projects have shared ownership, cooperative investments, and benefits appropriated from a solar farm among a crowd-sourced pool of small investors. Such projects are called Special Purpose Entity (SPE) models of community shared solar, where a team of investors collaborate in a market-based business enterprise to develop the community solar project [4]. The Solar Mosaic Project originating from Berkeley, CA has had recent success with crowd-sourced PV project development [4,22].

\section{Conclusions}

A large share of our resource systems are indeed managed through collective actions of local communities. Building façades and roofs are employed to integrate SECS technologies like photovoltaics, however larger commercial and multi-family structures in urban settings are area-constrained, leading to scarce solar electric resource units with allocation challenges for electricity appropriation. In addition, façade integrated photovoltaics with large solar fractions may not always present the highest solar utility for the building occupants or owners when balanced against other goals for daylighting and passive solar strategies. However, strategies are emerging to engage the space beyond the enclosure, by expanding our concepts of SECS networked into the collective infrastructure of the urban and surrounding rural environments.

We observe collective action strategies for managing solar technologies (as resource systems) emerging in local or state governments via progressive permitting for projects, utility sponsored community solar models, and code regulations; in community action through commons expansion and solar gardens; and via market-based strategies through investment in crowd-sourced solar projects. Solar energy resource systems are also increasingly managed through local sharing of information among the provisioning teams and appropriators of solar energy. The appropriators of solar energy find themselves 
interdependent among each other and tied to the power grid as a technological ecosystem, as well as the physical resource of the Sun. More SECSs installed for electricity generation means more information to share, and more incentive for structures to manage the increase in solar integration into society. Collectively, this signals the expansion of solar ecology as the study of interactions among solar energy conversion systems within the context of the environment, society, and technology.

\section{Acknowledgements}

The author thanks the guest editors for the opportunity to present this research topic for the Buildings audience.

\section{Conflicts of Interest}

The author declares no conflict of interest.

\section{References}

1. Carr, G. Sunny Uplands: Alternative energy will no longer be alternative. Available online: http://. economist.comnews/21566414-alternative-energy-will-no-longer-be-alternative-sunnyuplands (accessed on 7 July 2013).

2. Brownson, J.R.S. Solar Energy Conversion Systems; Academic Press: Amsterdam, The Netherlands, 2013.

3. Denholm, P.; Margolis, R. Supply Curves for Rooftop Solar PV-Generated Electricity for the United States; National Renewable Energy Laboratory: Golden, CO, USA, 2008.

4. Coughlin, J.; Grove, J.; Irvine, L.; Jacobs, J.F.; Phillips, S.J.; Sawyer, A.; Wiedman, J. A Guide to Community Shared Solar: Utility, Private, and Nonprofit Project Development; National Renewbal Energy Laboratory: Golden, CO, USA, 2012.

5. Ostrom, E. Governing the Commons: The Evolution of Institutions for Collective Action; Cambridge University Press: Cambridge, UK, 1990.

6. Cox, M. Balancing Accuracy and Meaning in Common-Pool Resource Theory. Available online: http://www.ecologyandsociety.org/vol13/iss2/art44/ (accessed on 22 September 2013).

7. Rayl, J.; Young, G.S.; Brownson, J.R.S. Irradiance co-spectrum analysis: Tools for decision support and technological planning. Sol. Energy 2013, 95, 364-375.

8. McNutt, P. Public goods and club goods. Encycl. Law Econ. 1999, 1, 927-951.

9. Kiesling, L.; Giberson, M. Electric network reliability as a public good. Perspectives 1997, 11, $1-7$.

10. Office of Electricity Delivery \& Energy Reliability Home Page. Available online: http://energy.gov/oe/information-center/educational-resources/electricity-101 (accessed on 30 August 2013).

11. Bradbrook, A.J. Future directions in solar access protection. Envtl. L. 1988, 19, 167.

12. Bronin, S.C. Solar rights. Boston Univ. Law Rev. 2009, 89, 1217:1-1217:49. 
13. Deru, M.; Field, K.; Studer, D.; Benne, K.; Griffith, B.; Torcellini, P.; Liu, B.; Halverson, M.; Winiarski, D.; Rosenberg, M.; et al. U.S. Department of Energy Commercial Reference Building Models of the National Building Stock; National Renewable Energy Laboratory: Golden, CO, USA, 2011.

14. Thornton, B.A.; Rosenberg, M.I.; Richman, E.E.; Wang, W.; Xie, Y.; Zhang, J.; Cho, H.; Mendon, V.V.; Athalye, R.A.; Liu, B. Achieving the 30\% Goal: Energy and Cost Savings Analysis of ASHRAE Standard 90.1-2010; Pacific Northwest National Laboratory: Richland, WA, USA, 2011.

15. U.S. Energy Information Administration. Commercial Buildings Energy Consumption Survey (CBECS) 2013. Available online: http://www.eia.gov/consumption/commercial/reports.cfm (accessed on 7 July 2013).

16. Gilman, P.; Dobos, A. System Advisor Model, SAM 2011.12.2: General Description; National Renewable Energy Laboratory: Golden, CO, USA, 2012.

17. Klein, S.A.; Beckman, W.A.; Mitchell, J.W.; Duffie, J.A.; Duffie, N.A.; Freeman, T.L.; Mitchell, J.C.; Braun, J.E.; Evans, B.L.; Kummer, J.P.; et al. TRNSYS 17: A Transient System Simulation Program. Available online: http://sel.me.wisc.edu/trnsys (accessed on 30 August 2013).

18. De Soto, W. Improvement and Validation of a Model for Photovoltaic Array Performance. Master's Thesis, University of Wisconsin, Madison, WI, USA, 2004.

19. Neises, T. Development and Validation of a Model to Predict the Temperature of a Photovoltaic Cell. Master's Thesis, University of Wisconsin, Madison, WI, USA, 2011.

20. Milun, K.; Spitler, K. Solar Commons. Available online: http://www.solarcommons.org/ (accessed on 7 July 2013).

21. Cohen, D.; Hughes, J. Solar Gardens Institute. Available online: http://www.solargardens.org/ (accessed on 6 July 2013).

22. Parish, B.; Rosen, D. Mosaic connects investors to high quality solar projects. Available online: http://www.joinmosaic.com (accessed on 20 July 2013).

(c) 2013 by the author; licensee MDPI, Basel, Switzerland. This article is an open access article distributed under the terms and conditions of the Creative Commons Attribution license (http://creativecommons.org/licenses/by/3.0/). 